\title{
"MÁS ÚTIL PARA LA ENSEÑANZA DE LOS NIÑOS": DOS IMPRESORES ANTE LOS TRIBUNALES REALES DE NAVARRA (1607-1608)
}

\author{
Javier Ruiz Astiz* \\ Universidad de Navarra
}

\begin{abstract}
Resumen: Durante el Antiguo Régimen la imprenta supuso un gran avance para la difusión de la cultura y la educación. Este hecho se pone de manifiesto si prestamos atención al enorme valor de las cartillas destinadas a la enseñanza de los niños. Su importancia provocó que fuese un producto muy demandado, por lo que todos los impresores trataron de controlar su producción para obtener grandes ingresos. Las disputas surgidas entre ellos nos hablan de un contexto en el que en numerosas ocasiones no fueron respetados los privilegios de edición existentes. En este artículo se analiza el enfrentamiento de Matías Mares y Carlos de Labayen ante los Tribunales Reales de Navarra por defender sus derechos.

Palabras clave: Cartilla; Matías Mares; Carlos Labayen; Reino de Navarra; privilegio; licencia.
\end{abstract}

\begin{abstract}
Title: "MÁS ÚTIL PARA LA ENSEÑANZA DE LOS NIÑOS": TWO PRINTERS FRONT THE REAL COURTS OF NAVARRE (1607-1608).

Abstract: During the Old Regime printing press was a great leap forward for dissemination of culture and education. This fact is evident if we pay attention to the enormous value of the primers designed to teaching of children their importance resulted in a product that was very demanding. All the printers attempted to control its production in order to obtain large income. Disputes arising between them speak to us of a context in which on numerous occasions were not respected the privileges of existing edition. This article discusses about confrontation of Matias Mares and Carlos Labayen front the Real Courts of Navarre to defend their rights.

Keywords: Primer; Matías Mares; Carlos Labayen; Kingdom of Navarre; privilege; license.
\end{abstract}

\section{INTRODUCCIÓN.}

A lo largo del Antiguo Régimen las autoridades navarras trataron de fiscalizar la venta fraudulenta de obras impresas, sometiendo a un cierto control la actividad desarrollada por impresores y libreros ${ }^{1}$. En todos aquellos lugares del reino en donde floreció el arte tipográfico se generalizaron toda una serie de prácticas nocivas para el bienestar de la industria libraria. Una de las situaciones más habituales, o que al menos con mayor dureza persiguieron las instituciones locales para frenar la comercialización de libros, fue la venta de obras prohibidas por parte de algunos profesionales. Sin embargo, mucho más frecuentes fueron las disputas que estallaron entre distintos impresores como consecuencia de la publicación y la posterior venta de ejemplares para las que determinados maestros no tenían privilegio de edición o licencia de impresión. Un hecho que también suscitó la preocupación de las instituciones navarras durante la Edad Moderna, pues trataron de ser más exhaustivas y rigurosas, aumentando así la vigilancia sobre los puntos de venta habituales ${ }^{2}$.

Dicho esto, lo que se pretende con este artículo no será mostrar la actitud de las autoridades navarras, sino que por encima de todo tratará de adentrar al lector en el complejo panorama editorial de principios del siglo XVII en la ciudad de Pamplona. Unas primeras décadas en las que nos encontramos a dos grandes impresores afincados en la capital del reino que rivalizaron entre sí entre 1607 y 1609. En dichos años tanto Matías Mares como Carlos de Labayen mantuvieron una enconada rivalidad, cuyo mejor testimonio es el proceso judicial que en 1607 interpuso el primero contra el segundo como consecuencia de la publicación de una cartilla para la enseñanza de los niños. Una obra para cuya explotación por diez años había conseguido Mares el privilegio en 1602.

Este suceso no debe hacernos olvidar que el libro no sólo era un producto editorial, sino que tanto para impresores como libreros era concebido como un negocio, algo que ya fue advertido por Moll ${ }^{3}$, y que desde su punto de vista ocasionó el estallido de multitud de conflictos ante los tribunales en defensa de sus intereses. No obstante, debemos tener muy presente el hecho de que detrás de muchas de aquellas controversias se encontró la posesión de privilegios o licencias para la publicación de determinados libros. Un aspecto, este último, sobre el que teorizó hace unos años Gonzalo ${ }^{4}$, quien nos habla en su estudio acerca de las vicisitudes que experimentaron los impresores al tener que solicitar tanto los privilegios como las licencias ante las autoridades competentes. De este modo, lo que se consigue es

\footnotetext{
*jruizastiz@gmail.com
} 
mostrarnos no sólo los avatares vividos por aquellos tipógrafos, sino al mismo tiempo el papel ejercido por las instituciones encargadas de aquellas prerrogativas en su intento por controlar la industria editorial.

Al margen de esto, resulta evidente que para llegar a comprender las distintas tensiones y disputas que estallaron entre los profesionales del libro debemos recurrir al estudio de los pleitos que se entablaron ante los Tribunales Reales, y que en la actualidad se encuentra depositados en el Archivo General de Navarra ${ }^{5}$. Como ya ha sido mencionado, el presente estudio gira en torno a un proceso judicial en el cual dos impresores lucharon por defender sus derechos, lo que sin duda redundaba directa y unívocamente en sus negocios. Desde mi punto de vista, considero que pese al complejo panorama legal y comercial que presenta el mercado editorial en el reino de Navarra, gracias al empleo de este tipo de fuentes podemos obtener considerables ventajas para la confección de este artículo:

- Permite conocer los valores sociales y morales desplegados en unas formas de pensar, sentir y actuar que son expresadas y justificadas en las alegaciones presentadas ante los jueces por los impresores, tanto para condenar un comportamiento delictivo por parte de los demandantes, como para excusarlo por parte de los acusados.

- Favorece llegar a comprobar la acción de la justicia durante el transcurso de los pleitos entablados, lo que nos permite tener constancia de la consideración social de los delitos y hasta qué punto los jueces siguieron los dictados de la legislación penal del reino.

- Posibilita la comprensión de los motivos reales que ocasionaron las denuncias que tuvieron lugar ante la publicación de libros sin contar con los privilegios de edición o sin licencias de impresión.

En definitiva, a través de este estudio lo que se pretende es acercar al lector a los entresijos del mercado librario de Navarra prestando atención a un caso llamativo dentro de las desavenencias que estallaron durante los siglos modernos entre los distintos profesionales del libro que estuvieron afincados en el reino. Al igual que resulta de sumo interés porque nos permitirá mostrar algunos datos que arroja el estudio de la documentación procesal sobre el éxito tanto de las cartillas como de las doctrinas cristianas como productos editoriales destinados a la enseñanza durante los siglos XVI y XVII.

\section{EL LIBRO COMO NEGOCIO: DISPUTAS ENTRE IMPRESORES.}

La industria editorial se erigió durante el Antiguo Régimen en una de las más boyantes en todo el continente europeo. Como se hace evidente, la invención de la imprenta permitía la multiplicación de los textos, con lo que ello suponía para la transmisión de conceptos de toda índole (religiosa, política, jurídica o educativa). Sin embargo, no debemos olvidar que el libro fue la piedra angular de un negocio en el que tomaron parte distintos protagonistas, desde el impresor hasta los autores, pasando por libreros y editores. Por tanto, toda publicación debe ser circunscrita a la obtención de una serie de ingresos monetarios.

El estudio de la industria editorial navarra desde este prisma nos permitir conocer algunos de los elementos que caracterizaron al mercado librario en aquellas centurias. No sólo nos ayuda a conocer las relaciones existentes entre impresores y libreros, sino también entre todas aquellas personas que se acercaban hasta ellos con la firme intención de publicar un libro. A lo que debemos añadir el hecho de que nos facilita la posterior comprensión de las posturas que manifiesten los distintos profesionales en lo que concierne al control editorial. Detrás de sus creencias en la defensa de sus derechos y en el ataque a las acciones llevadas a cabo por otras personas nunca debemos menospreciar el aspecto monetario. Por tanto, este apartado sirve para dar una imagen de conjunto de suma importancia en este artículo, ya que nos ayuda a explicar los motivos reales que existieron detrás de los argumentos que dieron Matías Mares y Carlos de Labayen en el transcurso del pleito en defensa de sus intereses.

Una vez sentadas estas premisas iniciales es preciso que seamos conscientes de las limitaciones que el mercado local provocó en algunos impresores que trabajaron en esta tierra, ya que muchos de ellos desempeñaron al mismo tiempo las funciones de librero o, incluso, de editor. La escasa demanda no permitió la especialización de muchos de ellos por los pobres ingresos que generaba su actividad. Sin embargo, encontramos algunos casos para el reino de Navarra de impresores que se dedicaron por entero a las labores de impresión. Nos estamos refiriendo a los tipógrafos que fueron contratados por las diversas instituciones del reino durante los siglos XVI y XVII, para quienes sí resultó económicamente viable mantener sus talleres gracias a los encargos recibidos.

Ser impresor oficial suponía múltiples ventajas, entre las que podemos nombrar por encima del resto el cobro anual de una cantidad estipulada para hacer frente a los gastos derivados de los trabajos desarrollados para las instituciones. Asimismo, ostentar ese cargo redundaba en la buena imagen del taller, lo que provocaba que recibiesen más encargos 
por la fama alcanzada. Igualmente resultó habitual que estos personajes fuesen beneficiados por las autoridades con la concesión de privilegios de edición en exclusiva, fruto de lo que podían llegar a obtener considerables ingresos. Y por último, si concebimos que este tipo de cargos suponían un exitoso rendimiento financiero para el impresor en cuestión, no lo era menos para sus descendientes porque se solía transmitir de padres a hijos, y también de maridos a mujeres que habían enviudado. En suma, lo que no hay duda es que estar bajo la protección de las instituciones del reino otorgó una gran estabilidad al negocio, lo que se traducía en menos penurias financieras que el resto de compañeros de profesión $^{6}$.

Para comprender de forma satisfactoria el conflicto que estalló en 1607 entre Matías Mares y Carlos de Labayen primero considero oportuno señalar que el primero de ellos se asentó en 1596 en la ciudad de Pamplona tras la muerte de Pedro Porralis. Desde la vecina Logroño llegó para acometer la edición de obras legales al ser nombrado impresor del reino, un cargo que ostentó hasta que en 1609 falleció. Lo cierto es que con él se inició una centuria de mayor esplendor que la anterior en lo que a la producción libraria se refiere. El asentamiento de las artes tipográficas en el reino se hizo patente, y muestra de ello fue la existencia de un número mayor de talleres que lucharon al mismo tiempo por dominar un mercado del libro que se estaba consolidando. Un hecho, este último, que jugaba en contra de los propios impresores, ya que la competencia iba en aumento y los posibles ingresos se verían repartidos. Hasta enero de 1607 Mares ostentó un dominio absoluto, pero aquel mismo año llegó a la capital del reino Carlos de Labayen al ser reclamado desde Zaragoza por el regimiento pamplonés. Al menos esto es lo que se evidencia de la reunión que mantuvo el pleno del consistorio el 13 de enero de ese mismo año:

\begin{abstract}
Dijeron que aunque la ciudad y reyno tiene conducido impresor para las costas que en él se pueden ofrecer siempre se ha tenido por falta no haber otro para que con la competencia tengan mejores letras e impresiones y hagan más comodidad a los que quisieren imprimir cédulas y otros despachos, y ahora es a su noticia que en la ciudad de Zaragoza del reyno de Aragón hay un impresor muy perito y hábil en este arte hizo de esta dicha ciudad y ha dado a entender vendrá a ella haciéndosele alguna comodidad y porque esto tenga efecto por el presente auto y su tenor le conducen por impresor de la dicha ciudad con la mitad del salario que se la da a Matías Mares, así bien impresor de la dicha ciudad que son veinte y cinco ducados pagados por sus tercios y tandas ordinarias de manera que los cincuenta ducados que se dan y han dado al dicho Matías Mares queden a medias para los dichos dos impresores y esta condución se entienda durante la voluntad del dicho regimiento como está la del dicho Matías Mares ${ }^{7}$.
\end{abstract}

Durante tres años compartieron ambos maestros el cargo de impresor oficial del reino y del regimiento pamplonés, lo que nos ayuda a comprender el malestar que ello habría ocasionado en Mares, dada la precaria situación financiera que esto le ocasionaba. Fruto de sus necesidades monetarias es muy posible que decidiese trabajar entre 1607 y 1609 para el Monasterio de Irache ${ }^{8}$. Cabe pensar, desde nuestro punto de vista, que ello pudo deberse al nombramiento compartido junto con Carlos de Labayen como impresor del regimiento pamplonés, por lo que dejó de ingresar 50 ducados para ser 25 ducados anuales. Por tanto, en este contexto de rivalidad profesional es donde debemos circunscribir el conflicto profesional que dirimieron ambos impresores con la publicación en el año 1607 de una Cartilla por parte de Labayen ${ }^{9}$, saltándose el privilegio que ostentaba desde hacía cinco años su competidor Marías Mares.

Lo que se hace evidente a través de este estudio es que en Navarra los libros de contenido jurídico-legal, religioso y pedagógico fueron vistos por los impresores y los libreros como toda una serie de géneros editoriales de sumo interés por los beneficios económicos que solían deparar dada la importancia de las obras a las que daban lugar. Sin duda alguna, la enorme variedad de títulos y de temáticas, así como la necesaria renovación o reedición de aquellas obras constituyó una auténtica oportunidad para paliar la escasez monetaria por la que atravesaron muchos profesionales. Sin embargo, en el caso que estamos analizando era el propio Mares quienes se quejaba por los perjuicios que le acarreaba en su hacienda la aparición del texto producido en las prensas de Labayen. En un escrito redactado por el demandante y que fue presentado durante el pleito señalaba que "he topado a un moço en esta ciudad vendiendo coplas y cartillas hechas por Carlos de Labayen", a quien "preguntándole yo de dónde las había comprado me respondió que de Vitoria, de casa de un librero y que tenía más de veinte resmas de ellas". Una situación que había ocasionado graves consecuencias en la hacienda familiar del demandante, ya que así lo advertía en su escrito: "solo una conformidad tengo yo y mi gente de no tener dineros que como vale el pan caro no gano para comer, que vale el cuartal de pan a real" 10 . 


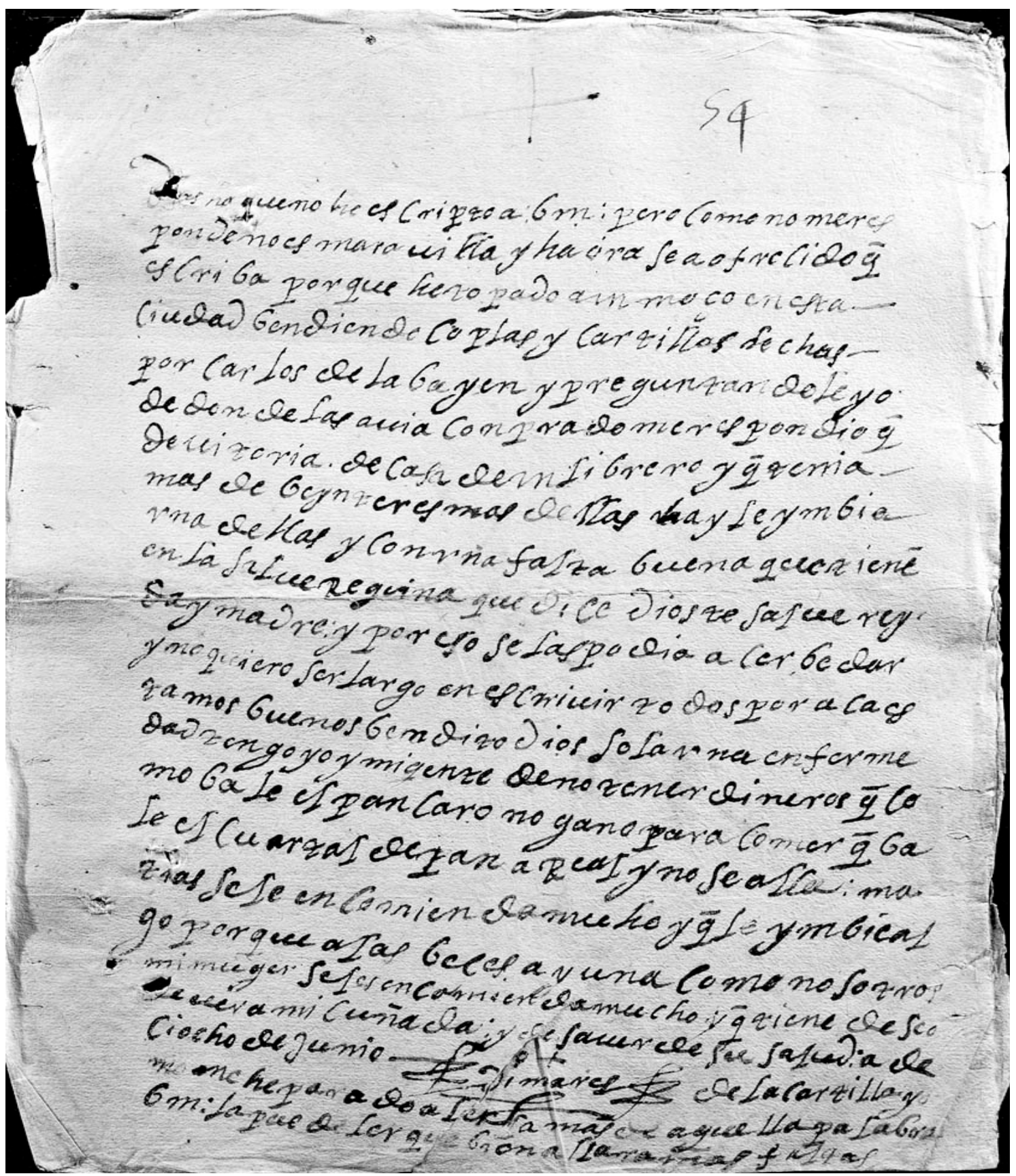

Figura 1. Carta manuscrita de Matías Mares. AGN, Tribunales Reales, Procesos, núm. 100528, fol. 54r.

Si bien el procurador de Matías Mares en el transcurso del juicio también manifestaba los perjuicios económicos acarreados a su defendido porque Labayen anteriormente "ha hecho diligencia para que el regimiento de la ciudad le quite como le ha quitado a mi parte la mitad del salario de cincuenta ducados que le da en cada un año, de que ha resultado muy grande daño para mi parte y por el contrario gran provecho para el adverso" ${ }^{11}$. Por lo tanto, el conflicto estallado en este caso fruto de la publicación de una Cartilla por parte de Carlos de Labayen no debemos dejar de contextualizarlo en toda una serie de sucesos que ponen de manifiesto el malestar latente entre ambos tipógrafos.

\section{EL PRIVILEGIO DE EDICIÓN: VULNERACIÓN DE LOS DERECHOS DEL IMPRESOR.}

En el contexto de la época el privilegio consistía en una concesión dada por el monarca o el Consejo Real ${ }^{12}$ para que una persona -normalmente el autor del libro-gozase durante una serie de años de la facultad de imprimir y vender una determinada obra en un territorio concreto ${ }^{13}$. Este aspecto resulta clave para comprender mejor los motivos que llevaron a Matías Mares a denunciar a Carlos de Labayen, puesto que a lo largo de estas líneas trataremos de entender 
todo privilegio de edición como algo más que un elemento de carácter administrativo, ya que debemos concebirlo también como un instrumento destinado al control editorial.

Resulta evidente que la posesión de éstos garantizaba a un impresor la imposibilidad de que otros profesionales del libro acometiesen la publicación de aquellas obras para las que ya existía un privilegio concedido. Asimismo, no debemos pasar por alto que uno de los motivos principales que guió a estos personajes a solicitar tales prerrogativas fue el deseo de afianzar los ingresos de su negocio con la idea de fortalecer su posición dentro del mercado editorial navarro. Como es obvio, existieron obras que pudieron reportar un mayor número de ingresos a sus promotores, por lo que resultó habitual que hubiese personas dispuestas a quebrantar los privilegios de sus poseedores. Detrás de aquellas prácticas se encontró la alta demanda de muchas de estas obras y la posibilidad de una venta más asequible para el público, lo que les aseguraba unas ventas importantes numéricamente hablando. Una situación que transgredía no sólo el orden legal imperante en el reino, sino que al mismo tiempo perjudicaba gravemente al detentador de dicho privilegio.

No sorprende, por tanto, que todo tipo de disputas aflorasen entre los impresores defendiendo sus posturas ante los jueces. En muchas ocasiones lo que se dirimía era el atentado contra un determinado tipógrafo que detentaba un privilegio de edición, por lo que se conservan testimonios de los pleitos que se interpusieron cuando alguien infringía las reglas y publicaba alguna obra sin contar con el permiso necesario, una práctica que claramente iba en contra de los derechos que atesoraban otras personas. Un hecho, este último, que fue resaltado por Mares en su demanda al señalar que desde enero de 1602 "por causas justas el Consejo Real dio al suplicante privilegio para que sólo él y no otro alguno imprima ni venda por diez años la cartilla de los niños que aprenden a leer". A lo que añadía que Labayen "quiere imprimir y ha comenzado la dicha cartilla en mucho daño del suplicante y de su privilegio". En consecuencia, y para defender sus prerrogativas, "suplica a vuestra majestad mande ver los autos del que se exhiben y proveer que el dicho Labayen ni otro alguno no se entremeta a imprimir ni vender la dicha cartilla so graves penas", siendo necesario además "se tomen a mano real los pliegos que se hayan impreso y los moldes, letras e instrumentos",

\section{Eartilla para eníñar alcra los niños, Eonla soctring Ebairtianaquefecanta, zamados bers manos,}

8gora benueuo eraminada,corregida, Y entrendads:y con priullegio oefu 200gentad inpretla. eses

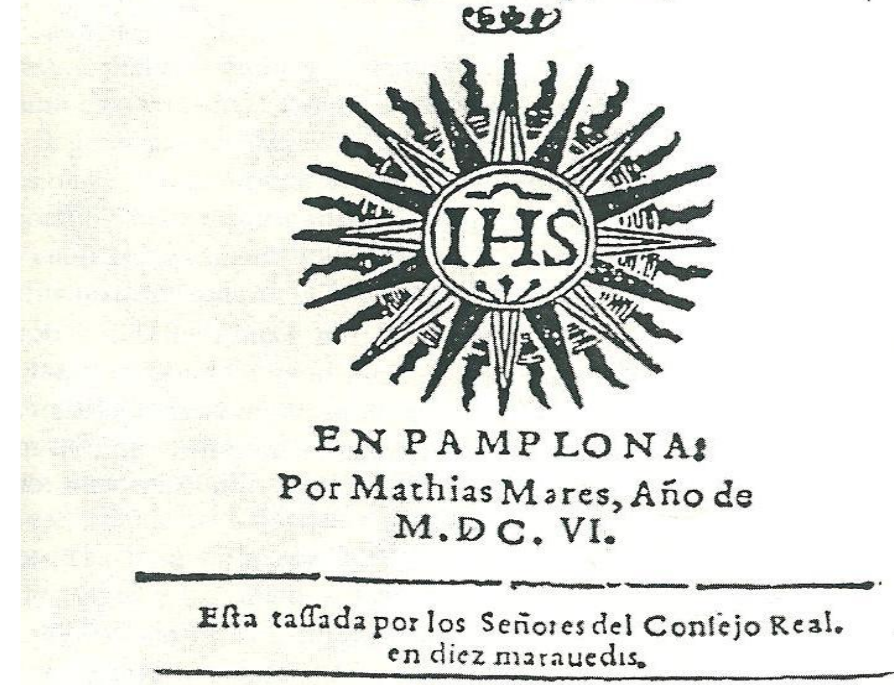

Figura 2. Cartilla impresa por Matías Mares en 1606 (procede del censo de cartillas de Infantes). 
Una opinión en la que se reafirmaba su procurador, Joan de Urrizola, quien alegaba que "es cierto que mi parte tiene privilegio concedido por el Consejo Real de este reino que sólo él pueda imprimir la cartilla de los niños y que nadie se entremeta en eso ni en venderlas ni haga comercio de ellas". A lo que posteriormente añadía que "mi parte ha usado del dicho privilegio y conforme a él ha impreso la dicha cartilla y la vende a precio muy acomodado". Por tanto, vemos como la defensa hecha ante los jueces gira en torno a la posesión de unas prerrogativas legales en exclusiva por parte de Matías mares, lo que le confiere una situación privilegiada al no contar con competencia en la impresión de las cartillas. En consecuencia, de forma acertada señalaba Urrizola que "si al dicho Carlos de Labayen se diese licencia para imprimir la dicha cartilla o impresa para venderla sería quitar a mi parte el dicho privilegio o revocárselo, y de ello le resultaría notable daño porque habría perdida la costa hecha en la dicha impresión que ha sido mucha". Además de todo esto, lo que solicita el procurador de Mares es que "en otras cosas podría el dicho Labayen ocuparse y ganar, sin que durante los años del privilegio quiera procurar que mi parte lo pierda"

Bien es cierto que la postura de la parte demandada era totalmente contraria, ya que Labayen argumentaba: "tiene pretensión el dicho Matías Mares que tiene privilegio y porque no tiene tal privilegio, y cuando lo tenga es de muy grande inconveniente impedir a los impresores el imprimir semejantes cartillas porque sería en daño notable de la república porque se venderían con muy grande exceso y desorden". A ello se sumaría el hecho de que su trabajo "quedaría infructuoso y sin provecho", pese a que lo más importante es que según apuntaba "en el tiempo de los predecesores impresores del dicho Matías Mares nunca se dieron tales privilegios y cuando le hubiera tal privilegio hubiera ido inserto en la dicha cartilla", por lo que solicitaba al juez "mande declarar no haber lugar lo en contrario pedido y que pueda libremente imprimir y vender las dichas cartillas" "16. No obstante, una vez oídas las dos partes en litigio el Consejo Real acordó el 10 de marzo de 1607 que el demandado "no las imprima durante el tiempo del privilegio" de Matías Mares, aunque le permiten que "las pueda vender" 17 .

Si uno analiza la evolución de la industria editorial en tierras navarras observa que hasta 1607 no coincidieron dos talleres de imprenta trabajando al mismo tiempo. Dicho esto, resulta obvio que la competencia que supuso la llegada de Carlos de Labayen a Pamplona ocasionase una mayor disputa por liderar el negocio librario en el reino. Por lo que no debe sorprendernos que nos encontremos con dos impresores enfrentados en los tribunales por la posesión y el disfrute de un privilegio. Es por todos conocido que durante los siglos XVI y XVII el sistema de privilegiar ciertas obras fue una herramienta legal que emplearon los monarcas en sus distintos territorios, pero que no estuvo ajena de polémica porque provocó todo tipo de disputas entre impresores y libreros ${ }^{18}$. Sin embargo, cualquier tipógrafo ambicionaba contar con el apoyo regio que suponía gozar de determinados privilegios de edición, pues era la mejor manera de poder afianzar sus negocios. En consecuencia, cabe afirmar que dichas prerrogativas legales se erigieron en una pieza clave en todo aquel entramado de intereses comerciales.

\section{LA LICENCIA DE IMPRESIÓN COMO ARGUMENTO ANTE LOS JUECES.}

El pleito seguía su curso y la parte demandada apoyaba su defensa recurriendo a la concesión de una licencia del Consejo Real que autorizaba la publicación de dicha cartilla. Sin embargo, en aquella época resultó frecuente que algunos impresores editasen textos sin contar con la licencia necesaria para ello, por lo muchos incurrieron en fraudes legales que fueron denunciados ante la justicia ${ }^{19}$. En nuestro caso, debo resaltar que desde la Pragmática de 1558 dada por Felipe II fue el Consejo Real de Navarra el encargado de controlar el mercado librario a través tanto de los privilegios como de las licencias. Como es obvio, la facultad de otorgarlas o no correspondía a dicha institución local, pese a que el trámite de solicitud fue idéntico al del resto de territorios de la Monarquía Hispánica. Por tanto, la autoridad civil del reino era la encargada de examinar los originales presentados por los autores, editores o impresores para acordar el proceso censor que debían superar. Así tras el riguroso examen superado, el Consejo dictaminaba si concedía o no la licencia al solicitante de la misma, lo que permitía la posterior impresión de la obra en cuestión.

La postura de Labayen se cimentaba en que él "imprimió la dicha cartilla con licencia particular del vuestro Consejo", a lo que añadía que "el privilegio que el dicho Matías Mares pretende tener no perjudica ni altera la licencia que tiene "20. Para ratificar su defensa el demandado presentó a lo largo del proceso la petición de licencia que cursó al Consejo Real en enero de 1607, en donde decía:

Sac. Mag. Carlos de Labayen, impresor, pide y suplica a V.M. le mande por licencia: para que pueda imprimir estos tres tratados, que son la Doctrina Christiana, compuesta por el padre Gaspar Astete de la Compañia de Iesus. La Exposición de Psalmo Miserere Mei. Por fray Luis de León, Cathedratico de Visperas en la Universidad de Salamanca. La Cartilla del $a, b, c$, con todo lo que en ella contiene. Atento de que esta holgando él y tres criados que tiene, que en ello recebira ${ }^{21}$. 


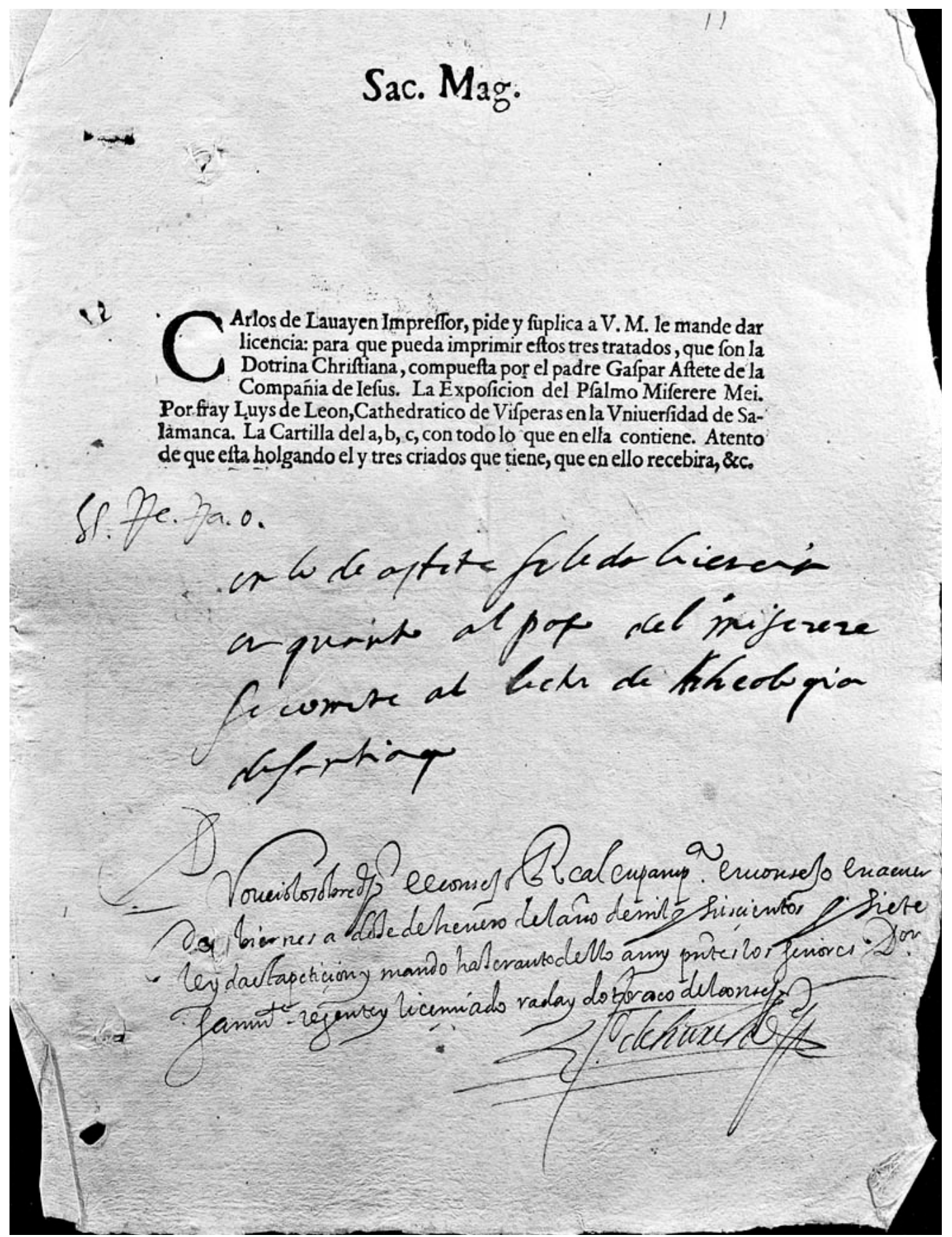

Figura 3. Licencia de impresión de Carlos Labayen. AGN, Tribunales Reales. Procesos, núm. 100528, fol. 11r.

Pese a ello, parece ser que únicamente le concedieron licencia para publicar la Doctrina Christiana de Gaspar de Astete. Un argumento que fue empleado por Joan de Urrizola para sentar las bases de las alegaciones presentadas por Matías Mares, pues según él en la petición de Labayen "donde habiendo pedido licencia para imprimir tres cosas la una la Doctrina Cristiana del padre Gaspar de Astete, y la exposición del Salmo Miserere por Fray Luis de León, y la Cartilla del a b c se le dio licencia para solo lo primero que es la doctrina, de manera que de hecho y sin preceder licencia real entremetido en lo susodicho de imprimir la dicha cartilla en perjuicio del privilegio" "22. Además lo que también pretendía Mares es que Labayen "no pueda despachar más de las cien cartillas que confesó tenía", aunque "tiene diez mil cartillas impresas y entregadas a libreros y otras personas en esta ciudad y fuera de ella, y ha vendido más de dos mil de ellas con mala fe",23. 
Dada esta situación Martín de Ozcáriz, procurador de Labayen, cambió de táctica y argumentó que la cartilla impresa por su defendido es una obra distinta porque "es muy diferente y diferente letra de la del dicho Mares", a lo que se sumaba el hecho del negocio, pues "le piden de las dichas cartillas en San Sebastián y en todas las provincias y Vizcaya" 24 , por lo que reitera que le den licencia para imprimir y vender cartillas. A lo que Joan Urrizola contestaba que Labayen "no puede quitar a mi parte contra su voluntad el derecho que ya tiene adquirido en virtud de las dichas sentencias y no hay nueva causa ni la pueda haber para que con agravio y perjuicio de mi parte pueda el dicho Carlos de Labayen vender más cartillas de las que se le permiten" 25 .

En su defensa, y tratando de demostrar que se trataba de un producto editorial distinto, el demandado presentó la petición de licencia que cursó al Consejo Real en marzo de 1608. En ella solicitaba:

Carlos de Labayen, vecino de la ciudad, suplica a vuestra majestad mande dar licencia para que pueda imprimir una relación de la jura que se celebró en la villa de Madrid del serenísimo Príncipe don Phelipe Dominico Victorio juntamente con una Cartilla y Doctrina Cristiana impresa en la villa de Valladolid atento que el suplicante no tiene ningunos muchos días con gran daño de su casa y familia y se las piden al presente de la villa de San Sebastián y Vitoria y para que pueda corresponder recibirá en ello merced ${ }^{26}$.

Una solicitud que según la parte demandante no había sido aceptada, ya que "en la petición que dio pidió dos cosas, la una se le diese licencia para imprimir la relación de la jura del serenísimo príncipe don Phelipe y esto pidió en primer lugar, y al fin de la dicha petición pide también licencia para imprimir una cartilla impresa en Valladolid y en el decreto solamente dice que se le da licencia para imprimirla conforme al original", por lo que Joan de Urrizola afirmaba que "así no fue visto dársela más de sólo para imprimir la dicha relación y es llano que no se le diera para la dicha cartilla por ser esto contra el dicho privilegio y sentencias" 27 .

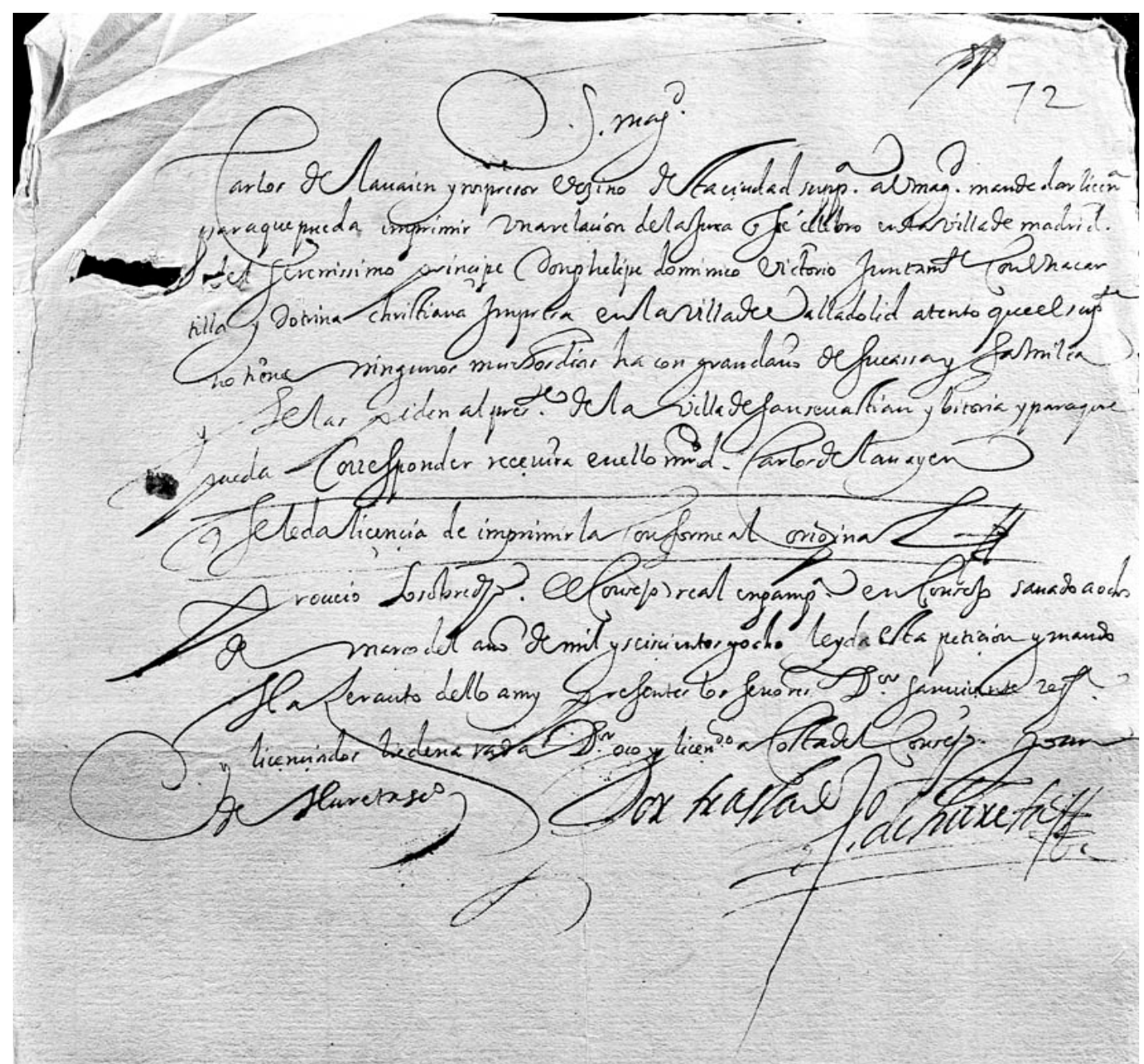

Figura 4. Licencia de impresión de Carlos Labayen. AGN, Tribunales Reales. Procesos, núm. 100528, fol. 72r. 
Fruto de aquella situación el juez emitió una primera sentencia en que "se multa al dicho Carlos de Labayen en cincuenta libras", a la vez que "se le manda no imprima ni venda ningún género de cartillas durante el tiempo del privilegio concedido al dicho Matías Mares", aunque también se indicaba que "las que tuviese impresas se tomen a nuestra mano real" 28 . En definitiva, lo que se ha comprobado es la importancia que atesoraron las licencias de impresión en la industria editorial, pues éstas se erigieron en uno de los métodos más eficaces que detentaron las autoridades del reino para controlar el mercado editorial. A lo que deberíamos unir el hecho de que también se erigió en un elemento que fue esgrimido en numerosas ocasiones por los profesionales del libro, ya que provocó numerosas tensiones entre ellos ${ }^{29}$. Gracias al control que ejercieron sobre las licencias no sólo cumplían con la legislación existente y colaboraban con las autoridades locales para mantener estable el entramado librario, sino que al mismo tiempo lograban proteger sus negocios de las intromisiones perpetradas por sus competidores.

\section{LA ACTITUD DE LA JUSTICIA: COTEJO DE LAS CARTILLAS.}

El empecinamiento de Carlos de Labayen le llevó a cambiar de procurador durante el pleito, y visto que el anterior no conseguía satisfacer sus exigencias encomendó su defensa a Pedro Ferrer, quien enseguida comenzó a demandar que le fuese permitido a su defendido publicar y vender la cartilla que Pedro de Laso había publicado en Valladolid ${ }^{30}$. De esta manera, lo que el demandado pretendía era que los jueces valorasen las dos cartillas como dos obras totalmente diferentes, por lo que así no incumpliría el privilegio otorgado a Matías Mares. Para apuntalar su táctica Ferrer argumentaba que "el privilegio del adverso porque aquel se le dio para la Cartilla que imprimió él y la contenciosa es diferente, de menos hojas y costa, y más manual", por lo que "el privilegio que se le dio limitadamente no se ha de extender a otras cartillas", ya que desde su punto de vista "es contra el bien común y en particular de los pobres, los cuales es bien que tengan cartilla de menos costa y que los compradores no estén obligados a comprar cartillas de más costa pudiendo haberlas de menos hojas y precio" 31 .

Ante esta situación el 8 de octubre de 1608 fue ordenado que Joan de Sada "vea y coteje las cartillas de ambas partes y haga relación por escripto con juramento por ante cualquier escribano real si son diferentes las unas de las otras y en qué se diferencian, y cuál de ellas es más útil para la enseñanza de los niños”,32. Dicho esto, resulta sumamente interesante mostrar las apreciaciones que Sada recogía el 10 de octubre tras efectuar su reconocimiento:

Yo he visto y reconocido por comisión del Real Consejo las dos cartillas de Matías Mares y Carlos de Labayen, impresores, y hallo que la cartilla de Carlos de Labayen tiene en algunas cosas mejor método y estilo para la enseñanza de los principios de leer como es en el alfabeto o abecedario de letras trocadas que así a de con otros dos abecedarios que al principio tiene de diferentes formas y las particularidades de la pronunciación de algunas sílabas que van con más distinción y claridad que la de Matías Mares importantes para la verdadera pronunciación de las distiones que se forman de ellas, demás que también los caractheres y forma de la letra de ella, es más perceptible, de mejor parecer, y más agradable a la vista, que es la razón porque en estos tiempos usan más las impresiones de estos caractheres y forma de la letra en las cossas de importancia que de ninguna otra, pero aunque assi que lleva añadidas algunas sílabas y con más distinction la cartilla de Labayen con todo esso tiene las sílabas contrarias de la segunda columna de la primera plana, menos la de Labayen que la de Mathias Mares, de más de esto le faltan a la de Labayen de la de Mathias Mares las cinco vocales y un abecedario de mayúsculas o letras capitales, y las oraciones dominicales tiene duplicadas en latín y romance, la de Mathias Mares y la de Labayen, no más de solo en romance, tiene demás de esto la cartilla de Mathias Mares la bendición de la mesa, el Magnificat con algunos puntos y advertimientos del ejercicio espirituales que deben hacerse cada día que a la de Labayen le faltan y aún que entre ambas cartillas tienen la doctrina christiana, la de Mathias Mares tiene algunas particularidades más, es cierto que en lo que toca el ayudar misa lo tiene cumplidamente la de Labayen para todo el discurso de la missa y la de Mathias Mares no más del introito, y así difieren estas dos cartillas, en lo que está dicho que quanto a la forma de letra y distinction de silabas el alphabeto trocado y el ayudar missa es mejor la de Labayen, pero quanto a lo demás y que está dicho está más cumplida la de Mathias Mares, de manera que para lo que es aprovechamiento de aprender a leer los niños tengo por mejor la cartilla de Labayen, pero quanto a la educación y ensenança de algunos otros ejercicios espirituales y buenas costumbras la de Mathias Mares, respecto de estar más cumplida y esta es la diferencia a que hay y lo que me paresce ${ }^{33}$. 


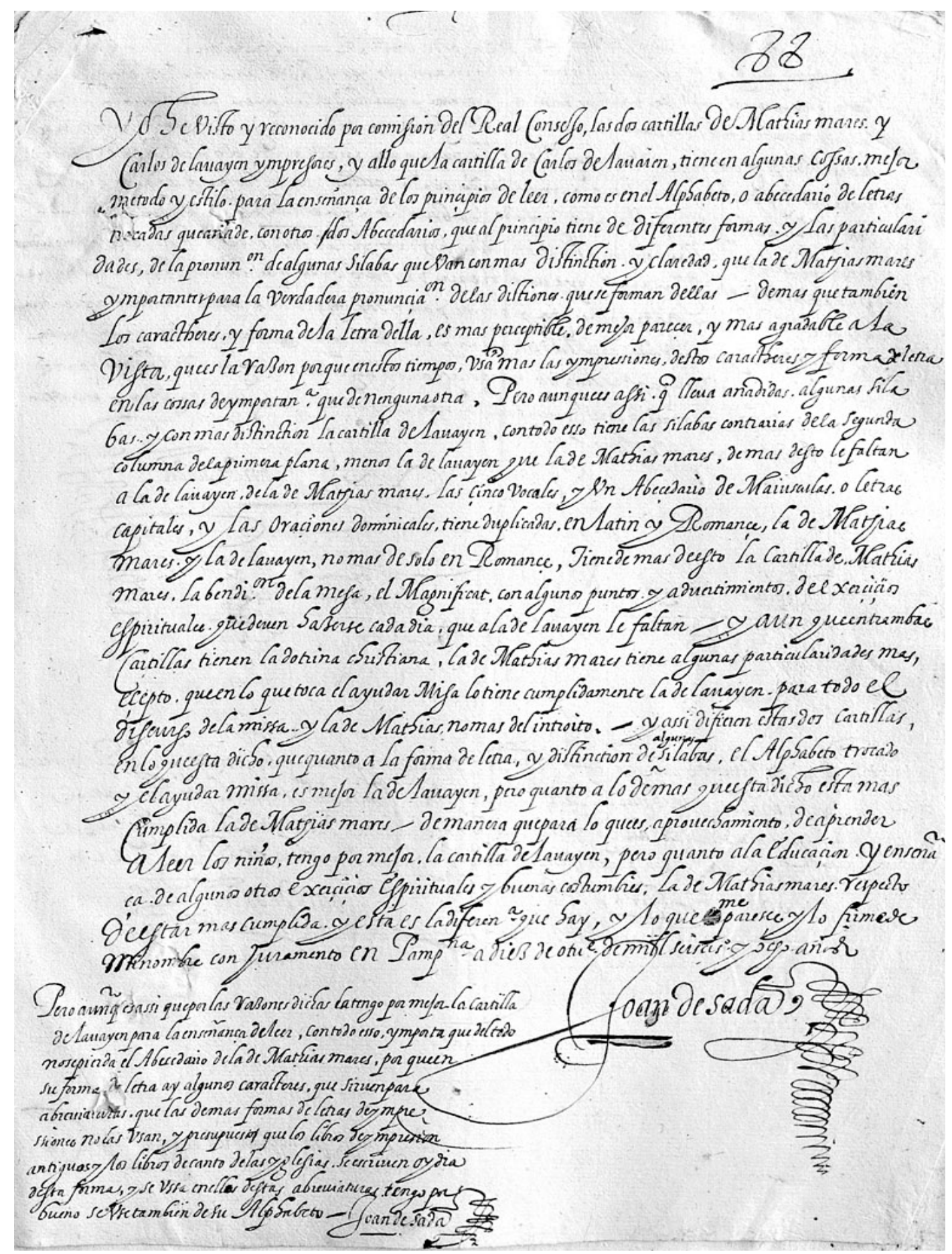

Figura 5. Cotejo efectuado por Joan de Sada. AGN, Tribunales Reales. Procesos, núm. 100528, fol. 88r.

Un cotejo tras el cual Joan de Sada concluía que "por las razones dichas tengo por mejor la cartilla de Labayen para la enseñanza de leer", aunque a favor de Mares afirmaba que "importa que del todo no se pierda el abecedario de la de Mathias Mares porque en su forma de letra hay algunos caracteres que sirven de abreviaturas que las demás formas de letras de imprenta no las usan", señalando además que "tengo por bueno se use también de su alphabeto"34. Sin embargo, el examen efectuado por Sada no le agradó a Matías Mares y su procurador alegó que "la diferencia de las letras que tiene la Cartilla de mi parte es de mayor importancia para que los niños que comienzan a leer se hagan a todo género de letras y no se olvide la lectura de letras góticas antiguas que se hallan en cualesquiera libros en particular en las impresiones que vienen de Italia y Francia, y a más de cien años que se usa la Cartilla de dicho mi parte". A su vez, apuntaba que "ambas cartillas son unas mesmas y la del dicho Carlos de Labayen es sacada y compuesta de la cartilla de mi parte y lo que le ha añadido es de poca importancia", por lo que "mi parte siendo 
vuestra majestad servido podrá añadir lo que el dicho Joan de Sada advierte, y lo hubiera hecho antes de agora si el susodicho u otra cualesquiera persona se lo advirtiera" ${ }^{35}$.

Pese a las alegaciones presentadas por Matías Mares las tácticas empleadas por Carlos de Labayen dieron sus frutos porque tras el reconocimiento se emitió una nueva sentencia, acordándose el 11 de octubre que "se le da licencia al dicho Carlos de Labayen para que pueda imprimir su cartilla por ser diferente de la cartilla de que se dio privilegio al dicho Mares"36. Comprobamos, por tanto, que los propios impresores eran conscientes del modo en que debían defender sus intereses profesionales. En este caso el impresor Carlos de Labayen consiguió obtener la facultad de poder imprimir una cartilla que había sido impresa en Valladolid unos años atrás porque el juez consideró que se trata de un producto editorial distinto, en el que entraban en juego diferencias notables de cara a la enseñanza de los niños. Hecho, este ultimo, que resultó crucial, tal y como se aprecia en las afirmaciones dadas por Joan de Sada al cotejar ambas cartillas. En suma, lo que se constata a través de este artículo es la defensa a ultranza que cada impresor hacía de su negocio, la cual podía llegar incluso a poner en entredicho el modelo del privilegio en exclusiva.

\section{EL VALOR DE LA ENSEÑANZA: CARTILLAS Y DOCTRINAS IMPRESAS EN PAMPLONA.}

Para aprender a leer durante el siglo XVII existió un género editorial inmejorable, como eran las cartillas y doctrinas cristianas ${ }^{37}$. Sin duda, a través de las Cartillas para enseñar a leer, los alumnos conocerían el abecedario, el silabario y algo de gramática, mientras que en las Doctrinas además de las oraciones nos podríamos encontrar con el alfabeto. Por tanto, a través de este tipo de productos editoriales los niños podían reconocer en los textos las letras, sílabas, palabras y oraciones, lo que les garantizaría un correcto aprendizaje ${ }^{38}$. Resulta muy interesante el censo efectuado por Infantes ${ }^{39}$, lo que nos permite reconstruir no sólo el fenómeno de la enseñanza en la Monarquía Hispánica durante la Edad Moderna, sino que, a su vez, nos permite establecer una tipología de este tipo de productos editoriales, así como también nos ayuda a trazar una evolución de los mismos.

Sin embargo, lo que se aprecia en las cartillas impresas entre Matías Mares y Carlos de Labayen es el hecho de que tanto la Cartilla como la Doctrina Cristiana se imprimen juntas a principios del siglo XVII. Un aspecto que Ruiz Pérez $^{40}$ ya lo advierte, pues según él este tipo de productos tenían una doble finalidad: formar en el aprendizaje de la lectura y fomentar la habilidad lectora con la aparición de textos catequéticos. Esta novedad no tenía otra meta que llegar a mejorar la enseñanza de los niños, ya que de lo contrario Joan de Sada no habría señalado que "en cotejar y reconocer las dichas cartillas" se ha visto "limitado en esto lo posible según el tiempo que me he ocupado", lo que desde su punto de vista era poco porque se trataba de una obra de tanta importancia para la sociedad "que merecía mucho más" 41 . Una relevancia que tampoco pasaba desapercibida para el procurador de Matías Mares, pues Joan de Urrizola apuntaba que si le concedían licencia al demandado habría diferentes cartillas, ocasionando "mucha confusión y que no se conformarán los maestros de escuelas en el modo de enseñar" ${ }^{42}$.

No obstante, ¿cuál es el número de cartillas real que existió? Si prestamos atención a los trabajos que Arigita y Pérez Goyena elaboraron en el siglo pasado comprobamos que Matías Mares publicó una Cartilla para enseñar a leer a los niños en 1606, pero en 1608 según ellos fue Carlos de Labayen quien publicó en dos ocasiones la Cartilla y Doctrina Cristiana. Si bien es cierto que del ejemplar de Mares tenemos constancia porque existe un ejemplar en la Hispanic Society de Nueva York, no podemos decir lo mismo de las que imprimió Labayen, pues no hay ningún testimonio consultable. De lo indicado por los expertos navarros se hace eco Víctor Infantes en su censo de cartillas, en donde para el siglo XVII recoge como posibles las dos que se le atribuyen a Labayen en 1608. Sin embargo, tras la consulta del proceso judicial que se conserva en el Archivo General de Navarra únicamente caben dos opciones posibles. Primero, que Arigita no datase bien las dos cartillas que dijo cotejar, ya que lo cierto es que en 1607 todo parece indicar que sí circuló una cartilla impresa por Labayen, por lo que podría ser que una fuese de ese año y la otra de 1608. Mientras que, como segunda opción, cabe la posibilidad de que Arigita datase bien esas dos cartillas que, según apunta, tuvo en sus manos, lo que haría pensar que Labayen habría publicado tres ejemplares; uno en 1607 y otros dos en 1608 .

Lo cierto es que todo esto son únicamente conjeturas que han surgido a raíz de la consulta del proceso judicial que dirimieron Matías Mares y Carlos de Labayen, las cuales espero poder resolverlas en futuras investigaciones. Sin embargo, considero que lo que se pone de manifiesto a través de los datos localizados es el más que posible error de Arigita $^{43}$, el cual han seguido reproduciéndolo numerosos expertos, caso de Pérez Goyena ${ }^{44}$ en su Ensayo de Bibliografía Navarra y, más recientemente, Infantes ${ }^{45}$ en su repertorio sobre las cartillas impresas en tierras hispanas durante los siglos modernos. Digo esto porque estimo que gracias a las referencias aportadas durante el transcurso del 
pleito es posible afirmar que Labayen pudo imprimir dos cartillas a lo largo de 1608, ambas siguiendo el modelo que se había traído desde Valladolid: una tras la petición de licencia cursada en marzo de ese año y la otra tras ser autorizado por el Consejo Real a partir del 11 de octubre. No obstante, de lo que no hay duda es que debió imprimir una cartilla nada más instalarse en Pamplona como impresor en enero de 1607, una época que coincide con la primera petición de licencia que cursó para publicar la cartilla. Además, tal y como se ha comprobado, fue la publicación de dicha cartilla por parte de Carlos de Labayen lo que motivó la denuncia presentada por Matías Mares ante los Tribunales Reales del reino de Navarra.

\section{CONCLUSIONES.}

A lo largo de los siglos XVI y XVII el libro se fue afianzando como un boyante y lucrativo negocio, lo que originó que quienes tomaban parte en la industria editorial, caso de los tipógrafos, se enzarzasen en muchas ocasiones en disputas profesionales que solían acabar ante los tribunales. El hecho de percibir la producción libraria de aquella época como una destacada fuente de ingresos monetarios nos permite comprender los distintos pleitos que se ocasionaron durante dichas centurias, en los que muchas veces aparecían los impresores defendiendo sus derechos y prerrogativas para la salvaguarda de sus negocios. Este es el caso de la demanda que Matías Mares interpuso en 1607 contra Carlos de Labayen ante los Tribunales Reales de Navarra, aunque también es cierto que el análisis de esta causa judicial nos ha puesto de manifiesto las tácticas que empleó la parte demandada para contrarrestar las argumentaciones dadas por el demandante y su procurador.

Lo cierto es que a través de este artículo se ha constatado la capacidad pleiteadora de los propios profesionales del libro, ya que en numerosas ocasiones se dedicaron a defender sus derechos ante las intromisiones llevadas a cabo por quienes rivalizaban con ellos mismos en el negocio editorial. Los impresores no dudaron en demandar a quienes iban en contra de sus intereses, pues no debemos olvidar que detrás de todo aquello no sólo estaba el hecho de la posesión de unas prerrogativas legales, sino principalmente el posible perjuicio económico para su negocio. Esta situación es la que nos permite entender que todos los personajes implicados en la industria editorial actuaron al mismo tiempo como agentes fiscalizadores, ya que junto a las autoridades del reino deseaban que el mercado librario no sufriese problemas derivados de la producción o la venta de ejemplares que se saltaban la legalidad imperante.

Si bien detrás de la causa judicial que ha sido objeto de estudio no se aprecia una crítica directa al mantenimiento de privilegios de impresión en manos de unos pocos impresores, sí que es cierto que se ataca el encorsetamiento y las dificultades que originaba de cara al desarrollo efectivo de la industria editorial. No cabe duda de que Carlos de Labayen era consciente de lo que suponía un privilegio de edición, y sin embargo defendió sus derechos porque consideraba que su obra era distinta en gran parte a la que gozaba del mismo, y que estaba en manos de Matías Mares desde 1602. En suma, no debe sorprendernos que la posesión de privilegios originase disputas entre maestros tipográficos, pues a través de ellos se ponía de manifiesto la preeminencia de unos sobre otros, así como la imposibilidad de publicar ciertos textos que podían ser de gran interés por los beneficios económicos que se derivaban de los mismos.

Por tanto, en el fondo de muchas disputas que surgieron durante estas centurias se evidencia que como causa final se encontraba la posesión de un determinado privilegio, ya que éste imposibilitaba la publicación de ciertas obras a otros impresores. Muestra evidente de estas tensiones es el pleito que ha sido estudiado en el presente estudio, aunque en el mismo también se determinan otros aspectos de sumo interés para una mejor comprensión de los conflictos en los que se vieron inmersos muchos impresores. Uno de estos es que conseguimos conocer la postura que adoptaron los titulares de dichos privilegios en la defensa de sus derechos frente a los transgresores de la legalidad, al igual que logramos tener constancia de los argumentos esgrimidos por quienes infringían la legalidad vigente. A su vez, otro de los temas que nos evocan sucesos de esta naturaleza es la importancia que los implicados daban a los perjuicios económicos que les acarreaba en sus negocios: por un lado, las consecuencias que acarreaba a los poseedores del privilegio la aparición fraudulenta de obras sin contar con su permiso o autorización, y por el otro, las limitaciones editoriales de quienes no poseían dicha concesión.

Sin embargo, uno de los puntos más relevantes que nos ha mostrado este artículo es la actitud de las autoridades respecto a la publicación y comercialización de obras fraudulentas, lo que se pone de manifiesto gracias a la propia acción de la justicia. De este modo, en una primera sentencia se indicaba que Carlos de Labayen ni publicase ni vendiese ningún tipo de cartillas hasta que no expirase el privilegio que ostentaba Matías Mares. Mientras que, posteriormente, una vez cotejadas y examinadas las obras publicadas por los dos impresores cambiaron las cosas, ya que autorizaron al demandado la impresión de la Cartilla y Doctrina Cristiana porque se trataba de una obra distinta para la que Mares había conseguido el mencionado privilegio. 
En definitiva, no cabe duda de que la judicatura debe ser concebida como un instrumento más al servicio de las autoridades del reino a la hora de controlar no sólo la producción de impresos, sino también de cara a vigilar la comercialización de los mismos en las librerías afincadas en Navarra. Lo que, a su vez, no es óbice para que la acción judicial no pueda ser considerada también como un elemento clave a la hora de dinamizar el mercado librario en estas tierras. Al menos, en este caso, así actuó la justicia local con la sentencia final que fue decretada a favor de Carlos de Labayen y en claro perjuicio de Matías Mares.

${ }_{2}^{1}$ Salcedo Izu (1982, p. 661)

${ }^{2}$ Asi lo recoge para el siglo XVI la profesora Ostolaza (2004) y para el siglo XVIII el trabajo elaborado por Itúrbide (2007).

${ }^{3}$ Moll (1987). Véase también Moll (1988).

${ }^{4}$ Gonzalo Sánchez-Molero (2009).

${ }^{5}$ De aquí adelante las referencias al Archivo General de Navarra se citarán de forma abreviada: AGN.

${ }^{6}$ Itúrbide Díaz (2007, p. 191).

${ }^{7}$ Archivo Municipal de Pamplona. Actas de Pleno (1596-1608), fol. 235.

${ }^{8}$ Delgado Casado (1996, p. 422).

${ }^{9}$ No se conserva ningún ejemplar de dicha publicación. El único dato que corrobora su existencia es que tanto Carlos de Labayen como Matías Mares durante el juicio declararon su publicación y posterior comercialización en el año 1607. Sin embargo, desde el trabajo de Arigita (1901) se ha pensado que Labayen únicamente publicó dos cartillas en 1608, un error que ha perdurado en los estudios posteriores de Pérez Goyena (1947) e Infantes (2003).

${ }^{10}$ AGN, Tribunales Reales. Procesos, núm. 100528, fol. $54 r$.

${ }^{11}$ AGN, Tribunales Reales. Procesos, núm. 100528, fol. 10r.

12 Salcedo Izu (1964, p. 164).

${ }^{13}$ Véase Reyes Gómez (2000, p. 95).

${ }^{14}$ AGN, Tribunales Reales. Procesos, núm. 100528, fol. $1 r$.

${ }^{15}$ AGN, Tribunales Reales. Procesos, núm. 100528, fol. $10 \mathrm{r}$.

${ }^{16}$ AGN, Tribunales Reales. Procesos, núm. 100528, fol. $12 r$.

${ }^{17}$ A GN, Tribunales Reales. Procesos, núm. 100528, fol. $14 r$.

${ }^{18}$ Reyes Gómez (2001, p. 179).

${ }^{19}$ Conde Naranjo (2006, p. 314).

${ }^{20}$ AGN, Tribunales Reales. Procesos, núm. 100528, fol. 2r.

${ }^{21}$ AGN, Tribunales Reales. Procesos, núm. 100528, fol. 11r.

${ }^{22}$ AGN, Tribunales Reales. Procesos, núm. 100528, fol. $16 \mathrm{r}$.

${ }^{23}$ AGN, Tribunales Reales. Procesos, núm. 100528, fol. $18 \mathrm{r}$.

${ }^{24}$ AGN, Tribunales Reales. Procesos, núm. 100528, fol. $28 r$.

${ }^{25}$ A GN, Tribunales Reales. Procesos, núm. 100528, fol. $30 r$.

${ }^{26}$ AGN, Tribunales Reales. Procesos, núm. 100528, fol. 72r.

${ }^{27}$ AGN, Tribunales Reales. Procesos, núm. 100528, fol. $74 r$.

${ }^{28}$ AGN, Tribunales Reales. Procesos, núm. 100528, fol. $81 r$.

${ }^{29}$ Véase para el caso castellano el reciente estudio de Bouza (2012, p. 188).

${ }^{30}$ Sobre esta cartilla cabe destacar el estudio de Resines (1987, p. 116), asi como Resines (2007).

${ }^{31}$ AGN, Tribunales Reales. Procesos, núm. 100528, fol. $83 r$.

${ }^{32}$ A GN, Tribunales Reales. Procesos, núm. 100528, fol. $86 r$.

${ }^{33}$ AGN, Tribunales Reales. Procesos, núm. 100528, fol. 88r.

${ }^{34}$ AGN, Tribunales Reales. Procesos, núm. 100528, fol. $88 \mathrm{v}$.

${ }^{35}$ AGN, Tribunales Reales. Procesos, núm. 100528, fol. 89 r.

${ }^{36}$ AGN, Tribunales Reales. Procesos, núm. 100528, fol. 90r.

${ }^{37}$ Sobre la distribución de las cartillas en la Monarquía Hispánica durante el siglo XVII merece la pena consultar el estudio de Moll (1987, p. 323).

${ }^{38}$ Herrero Jiménez; Diéguez Orihuela (2008, p. 80).

${ }^{39}$ Infantes (2003, pp. 14-15).

${ }^{40}$ Ruiz Pérez (2003, p. 57).

${ }^{41}$ AGN, Tribunales Reales. Procesos, núm. 100528, fol. $88 \mathrm{v}$.

${ }^{42}$ AGN, Tribunales Reales. Procesos, núm. 100528, fol. $89 \mathrm{v}$.

${ }^{43}$ Arigita (1901, p. 76, $n^{\circ} 130$ y 131).

${ }^{44}$ Pérez Goyena (1947, II, p. 107, $n^{\circ} 246$ y 247).

${ }^{45}$ Infantes (2003, p. 68). 


\section{Bibliografía}

ARIGITA LASA, M. Bibliografía navarra. Descripción de las obras impresas en este antiguo reino, desde el descubrimiento del arte tipográfico hasta nuestros días. Pamplona: Imprenta Provincial, 1901.

BOUZA ÁlVAREZ, F. "Dásele licencia y privilegio”. Don Quijote y la aprobación de libros en el Siglo de Oro. Madrid: Akal, 2012.

CONDE NARANJO, E. El argos de la monarquía: la policía del libro en la España ilustrada (1750-1834). Madrid: Centro de Estudios Políticos y Constitucionales, 2006.

DELGADO CASADO, J. Diccionario de impresores españoles (siglos XV-XVIII). Madrid: Arco Libros, 1996, Vol. I.

GONZALO SÁNCHEZ-MOLERO, J. L. Los impresores ante el Consejo Real: el problema de la licencia y del privilegio (1502-1540). En Actas de la XIII y XIV Jornadas Bibliográficas Bartolomé Gallardo. Badajoz: Unión de Bibliófilos Extremeños, 2009, pp. 119-184.

HERRERO JIMÉNEZ, M.; DIÉGUEZ ORIHUELA, M. Primeras letras. Aprender a leer y escribir en Valladolid en el siglo XVI. Valladolid: Universidad de Valladolid, 2008.

INFANTES, V. La memoria impresa de la enseñanza. En INFANTES, V.; MARTÍNEZ PEREIRA, A. (eds.). De las primeras letras. Cartillas españolas para enseñar a leer del siglo XVII. Salamanca: Universidad de Salamanca, 2003, Vol. I, pp. 13-29.

INFANTES, V.; MARTÍNEZ PEREIRA, A. (eds.). De las primeras letras. Cartillas españolas para enseñar a leer del siglo XVII. Salamanca: Universidad de Salamanca, 2003.

ITURBIDE DÍAZ, J. Escribir e imprimir. El libro en el reino de Navarra en el siglo XVIII. Pamplona: Gobierno de Navarra, 2007.

MOLL, J. De impresores y libreros: un pleito de 1651. En Varia bibliographica: homenaje a José Simón Díaz. Zaragoza: Kassel, 1988, pp. 483-490.

MOLL, J. La Cartilla et sa distribution au XVIIème siecle. En De l'alphabétisation aux circuits du livre en Espagne aux XVI-XIXe siècles. Paris: CNRS, 1987, pp. 311-332.

OSTOLAZA ELIZONDO, M. I. Impresores y libreros en Navarra durante los siglos XV y XVI. Pamplona: Universidad Pública de Navarra, 2004.

PÉREZ GOYENA, A. Ensayo de bibliografía Navarra desde la creación de la imprenta en Pamplona hasta el año 1910. Pamplona: Diputación Foral de Navarra, 1947, Vol. II.

RESINES LLORENTE, L. La catedral de papel: Historia de las cartillas de Valladolid. Valladolid: Diputación de Valladolid, 2007.

RESINES LLORENTE, L. Las cartillas de la doctrina Cristiana de Valladolid. Revista de Folklore, 1987, nº 76, pp. 111-118.

REYES GÓMEZ, F. Con privilegio: la exclusiva de edición del libro antiguo español. Revista General de Información y Documentación, 2001, vol. 11, $n^{\circ}$ 2, pp. 163-200.

REYES GÓMEZ, F. El libro en España y América: legislación y censura (siglos XV-XVIII). Madrid: Arco Libros, 2000.

RUIZ PÉREZ, P. De las primeras letras a las letras. En INFANTES, V.; MARTÍNEZ PEREIRA, A. (eds.). De las primeras letras. Cartillas españolas para enseñar a leer del siglo XVII. Salamanca: Universidad de Salamanca, 2003, Vol. I, pp. 49-64.

SALCEDO IZU, J. La imprenta en la legislación histórica de Navarra. En Historia de la imprenta hispana. Madrid: Editora Nacional, 1982, pp. 645-677.

SALCEDO IZU, J. El Consejo Real de Navarra en el siglo XVI. Pamplona: Rialp, 1964. 